\title{
Discussion Forum \\ From pillars to posts: Some reflections on Community Service six years on
}

Claire Penn, Anniah Mupawose and Jennifer Stein

University of the Witwatersrand

\begin{abstract}
Speech-Language Therapy and Audiology graduates have worked in Community Service for 6 years. An evaluation of the impact of this strategy is now seen as important. In this discussion paper we report on the content and process of feedback sessions with 132 graduates from the University of the Witwatersrand during their community service placements from 2003-2008. Experiences and perceptions of these graduates are discussed in relation to a model as well as in relation to additional research conducted with our profession and other Community Service professions. Themes discussed include professional and technical issues, systemic and managerial issues, interpersonal issues and ethical issues. Perceptions on the adequacy of training are also described. The overall goals of Community Service are considered as well as indices for measuring success. Implications are considered for training institutions, for the Department of Health and for the profession.
\end{abstract}

\section{Key words: Community service, speech language therapy and audiology, perceptions, ethical distress}

$\mathrm{n}$ this discussion paper we reflect on the first six years of community service from the perspective of graduates of the University of the Witwatersrand (Wits). In line with our title, we will reflect on how the pillars of primary health care have been addressed and how community service posts have helped our graduates achieve experience and competence in these areas.

Community service (CS) was first introduced into South Africa for newly qualified doctors in 1998, followed by dentists in 2000 and pharmacists in 2001. In 2003, seven more professions, including our own, started doing community service. The goal of CS was to "distribute health personnel throughout the country in an equitable manner" (Department of Health, 1997) and "to ensure' improved provision of service to all the citizens of our country". The aim was also "to provide our young professionals with an opportunity to develop skills, acquire knowledge, behaviour patterns and critical thinking that will help them in professional development". A further implicit aim for CS was in counteracting (or at least delaying) emigration trends of health professionals (Reid, 2000).

The history of CS has been well documented and published accounts suggest that it has generally been successful in achieving its goals (Bateman, 2004). There has been ongoing debate, evaluation and feedback on the process and the pitfalls have been examined by a number of professional groups including doctors (Bateman, 2004; Nemutandani, Malulueke \& Rudolph, 2006; Reid, 2001), dieticians (Paterson, Green \& Maunder, 2007), dentists (Naidoo \& Chitke, 2002) and pharmacists (e.g. Khan, 2002). In view of the fact that over 700 graduates from our own professions of Speech-Language Therapy and Audiology (SLT/A) have to date completed CS (Department of Health, fig- ures retrieved from www.hst.org.za/search/basicresult.pho). we believe that it is time to undertake such a review for our own professions. Some feedback on the process of CS for our professions has already occurred at various national and regional fora and through the website of the South African Speech Language Hearing Association (SASLHA) (see for example the feedback from UCT graduates Claire Roberts, Sarah Skeen and Stellenbosch graduate Katherine Richardson on this website: Roberts, no date). In this paper we intend to formalize the feedback we have received from our own graduates and propose a model of interpretation, while linking this with some formal research studies done on specific aspects of the experience (Ellis, 2004; Koorts, 2004; Naidoo, 2006).

The role of the Department of Speech Pathology and Audiology at Wits in community work has a long history. Not only did it host the first national conference on the topic (Schneider, 1992) but it ran the diploma course for community speech and hearing therapy for 10 years (Bortz, Schoub \& McKenzie, 1992). In addition, the Department was involved for a number of years in the training of community-based rehabilitation workers at IUPHC site in Alexandra as well as at Tintswalo Hospital in Mpumalanga (Schneider, 1992; Rule, Lorenzo \& Wolmarans, 2006). These experiences informed the content and methods of our undergraduate teaching. For the past six years, aided by funding from an endowment, we have hosted a feedback session in the middle of the CS year for our graduates. This feedback session has (with the exception

Contact:

Prof Claire Penn, Department of Speech Pathology and Audiology University of the Witwatersrand

Johannesburg

South Africa

e-mail: Claire.Penn@wits.ac.za 
From pillars to posts: Some reflections on Community Service six years on

of one year) taken place either in late May or early June of the graduates' community service year. The purpose of these feedback sessions has been to gain insight into the issues of concern in practice and to ascertain graduates' views on their clinical and theoretical preparation for practice. This feedback has helped the Department to modify and focus its syllabus where necessary in contextually relevant areas. It has also provided feedback on content and methods of teaching which has informed the ongoing process of curriculum development.

In this paper we aim to collate this feedback and to demonstrate the outcome of this reflective process as well as to consider trends in our profession, and how the experiences of our graduates match those of other health professionals undertaking CS.

\section{Participants}

Over the 6 years in which we have held this feedback session (2003-2008), we have had 132 CS graduates from Wits participating in the sessions. This group represents approximately $74 \%$ of all our graduates over this period and constitutes just under a quarter of all SLT/As who have been working in CS since its inception. During this period they have worked in most provinces (Gauteng, Mpumalanga, Limpopo, Eastern Cape, Western Cape, North West province, Free State and KwaZulu Natal). About two thirds of the posts have been hóspital based but each year there have been some regional posts (ranging from 6-12 per year).

Each participant attended the one day workshop and was asked to present some feedback to staff and final year students on their experience according to certain broad headings pertaining to their caseloads, challenges, perceived obstacles and facilitators. They were also asked to comment on their perceived level of. preparedness and the adequacy of their undergraduate training. Participants had been urged in advance to indicate areas in which they would like extra input and some workshops led by staff were also offered during the visits. At some of these feedback workshops, there were visitors, including representatives from the Department of Health (DoH), members of the professional board of the Health' Professions Council of South Africa (HPCSA), hospital supervisors, other professionals undertaking CS (e.g. occupational therapists) and speech therapy graduates from other universities also undertaking CS. Each feedback session afforded a constructive opportunity for participants to share and discuss their experiences, to seek assistance and to problem-solve around common issues. The final year students in the Department who also attended were thus provided with an opportunity to find out about their forthcoming positions. The role of the teaching staff and the visitors in these feedback sessions was supportive and students were provided with input supplemented by follow up phone calls and site visits on occasion.

\section{Analysis of data}

During each feedback session, detailed auditing of the process took place. At least two staff members made notes on each occasion and a permanent record was retained of the collated notes. These records were subsequently used as a basis for curriculum meetings, were discussed each year at the respective interuniversity meetings and were also used in feedback to relevant bodies such as the Department of Health and the HPCSA. It is these cumulative records which were used for the purpose of the present analysis. Following the suggestions of Patton (1990) and Aronson (1994), a thematic content analysis was undertaken on the 6 sets of notes. In line with the areas broadly covered in each student presentation, various themes emerged. These themes have been aligned with other professions' analyses of CS issues (see for example Reid, 2002) and will be presented in the following section. We will also highlight trends across the 6 year period. We will supplement this discussion with some direct quotations from the graduates.

\section{Results}

The themes derived from the analysis have been presented in relation to the model portrayed in Figure 1.

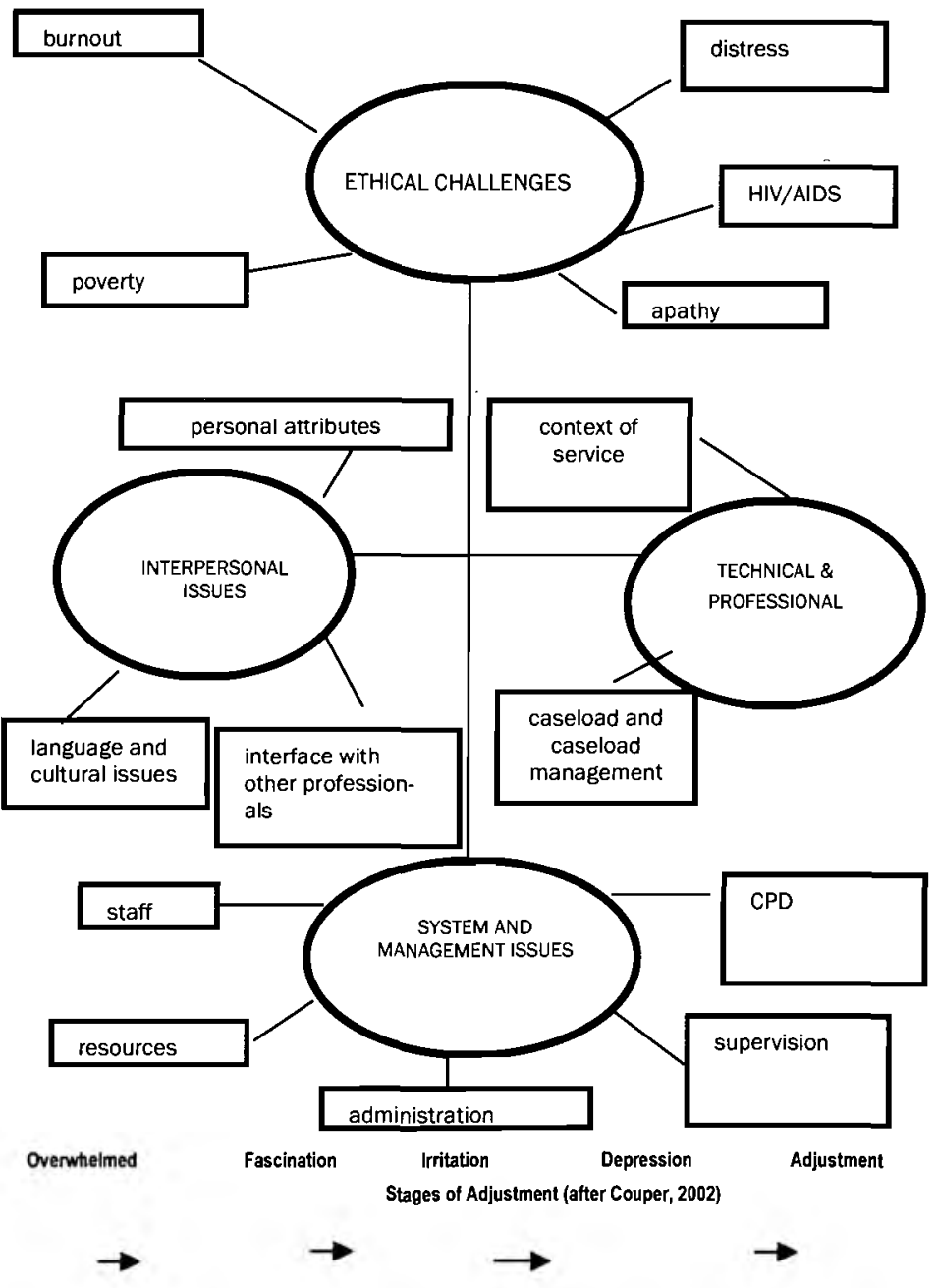

Figure $1 \mathrm{~A}$ diagrammatic representation of major themes and influences affecting Community Service for SLTAs 
This model is based on a similar model produced by the Task Team in Department of Health in 2001 (Reid, 2002) but has been adapted specifically for our professions to include the recurrent major themes arising from our analysis. It highlights four major aspects of concern - those relating to technical and professional aspects of service delivery, those related to system and management issues, those concerned with personal and interpersonal relations (what the above Task Team rather inappropriately, in our opinion, referred to as "Soft Skills") and ethical aspects. Each component of this model will now be discussed and illustrated.

\section{Technical and professional issues}

\section{Context of service}

As predicted, the range of responses was vastly diverse and depended a great deal on the placement of the graduate. In some cases, graduates were assigned to posts in departments which were already established and in which there were full time posts, as well as senior staff who were able to act as mentors and supervisors. In other cases, especially in the regional positions, the community therapists were the first ones from our profession servicing that particular community and they had to establish services from scratch, often without the benefit of a disciplinerelated supervisor.

Most graduates indicated that they were doing both Speechlanguage therapy and Audiology and they indicated that in most settings there was a strong demand for Audiology services. At the beginning of CS (2003 and 2004) graduates reported the availability of very limited equipment. At some sites this improved. However even when equipment was ordered, it sometimes was "still in plastic" because of space restrictions. There was a strong feeling that the lack of equipment together with a lack of ENT services hampered opportunities for doing Audiology. These observations correlated with the findings of Naidoo (2006) who in her survey of 278 audiologists in practice throughout South Africa (including 9 in CS) in 2005, found that fewer than $25 \%$ felt that they had the necessary access to equipment which would enable them to do more than basic audiological testing. Similarly Claire Roberts, an audiologist from another programme, reported that during her CS year "about $30 \%$ of my time was spent doing audiology" (Roberts, no date).

\section{Caseload and caseload management}

The size of caseloads varied according to site. During the initial years, some of the graduates in some sites reported that there was not enough work for them and they had to create it. Some experienced initial problems with referrals in the context of new posts and reported on the implementation of awareness campaigns. Very high caseloads were reported at the regional clinics. Recently some graduates in this setting have even complained about difficulties in prioritizing and in "over-referral":
"Everything is referred to speech therapy even if we can't do anything about it."

Graduates consistently commented on the very high incidence of individuals with cerebral palsy and of multiple handicap. Many graduates have seen patients with syndromes that they had not seen before. Many were involved in early intervention and in paediatric dysphagia. In some hospital settings graduates indicated that up to $80 \%$ of their inpatient caseloads had dysphagia.

In a study conducted by Koorts (2004) with 23 graduates (from two universities) undertaking their community service in 2004, the following aspects were found to reinforce these impressions: $92 \%$ of the SLT/As in CS were working with clients with dysphagia and such patients constituted between $26-76 \%$ of their caseloads. The main etiologies in adults were stroke, traumatic brain injury (TBI) and head and neck cancer, and for children, developmental problems. Only four reported using any measures other than bedside evaluation and many felt under-prepared for this aspect. $77 \%$ of the group indicated that they were entirely unsupervised in their dysphagia work.

Graduates also reported a high incidence of CVA and TBI as well as chronic otitis media. The HIV /AIDS epidemic was a pervasive theme in the discussions of caseloads and all graduates have expressed how difficult this disease has been to handle, both professionally and personally. Amongst themes identified in relation to HIV/AIDs were concerns about the attitudes of other professionals to some of the patients. They also felt that they did not know enough about the treatment of the disease. These findings relate to the detailed analysis of Benatar (2004) with regard to the impact of this disease on health care delivery in South Africa.

Graduates commented on the value of group work in address ing caseload demands. Several graduates reported on initiatives which included the starting of new clinics, kangaroo mother care, hearing screening at nursery schools, cerebral palsy schools, school-aged language groups, language stimulation groups, sign language groups, groups for caregivers, education for pregnant mothers, nurse training, educational talks for teachers and the development of a library for patients in a rehabilitation ward. Cooption by other professionals for counselling services and serving as Sign Language interpreters for other professionals working with deaf clients, were among the expanded roles reported.

"You are more than a speech therapist; you have a broader role - get involved!"

\section{System and Management issues}

On the whole, feedback with regard to placement issues was positive. The graduates felt that they had been consulted and informed, and their choices had been taken into account. Most of 
From pillars to posts: Some reflections on Community Service six years on

them had their placements in good time (by September of the year before) and there was some flexibility which was appreciated. Although some early difficulties were reported, a positive change was noted over the years in this aspect - with improved lines of communication as well as good organization and briefing. No major complaints were made regarding payment, leave conditions, accommodation arrangements or allowances.

\section{Administration}

A common theme was the perceived burden of administrative duties which many graduates initially found overwhelming. They also expressed a lack of preparation in this regard. Ellis (2004), who undertook a survey of 15 Wits STA graduates in 2004, provided some strong evidence of this in her telephonic interviews:

"I was thrown in the deep end."

One of Ellis informants' also indicated that in retrospect, "I would be more systematic in record keeping".

\section{Resources and staff}

Early graduates in CS described the challenges of having to set up services and departments "from scratch"- some had "not even a desk". Such graduates had to use their own equipment or borrow equipment from others. Some reported making equipment from waste. For therapists in regional placements a particular and recurrent problem related to the use of transport. They reported that much of their work time was spent travelling. Further they reported that the government cars frequently broke down and were not repaired timeously. Often multidisciplinary teams travelled together in one vehicle and there was a perception that time was wasted while waiting as a colleague from another discipline was treating a patient.

Space shortages were frequently commented on and concern was expressed about the long waiting list for hearing aids, for example, and the adverse effects of budget cuts on the acquisition and supply of hearing aids.

Generally, over the years we noticed a reported improvement in referral systems for under-resourced placements (e.g. regional centres) to better equipped hospitals. In some settings, graduates felt overburdened by referrals from other therapists in their region who, either because of their scope of practice (on single registers) or their lack of equipment, referred large caseloads for assessment. In the feedback many graduates reported on staffing issues at their sites and the way in which such issues impacted on their goals of service delivery. Distressingly, many encountered obstacles which linked to poor morale of permanent and nursing staff and major staff shortages resulting in backlogs and inefficiencies. Nevertheless, advice proffered included:

"Make friends with everybody in the hospital" and "Build rapport with the nurse."

Graduates reported many problems with referrals especially specialist referrals (including ENT and Neurology).

\section{Supervision}

As Reid (2002) reports in relation to doctors, the level of supervision has been very variable. All graduates reported the need for supervision, particularly for disorders such as dysphagia. They were often supervised by another profession (e.g. social work) who did have insight into the scope of our professions.

"The work was extremely depressing and we were not offered any type of debriefing or counselling which I think is essential."

Each cohort of graduates relied a great deal on each other through telephonic and e-mail contact. Interestingly the mid year feedback opportunity itself (on which this study is based) provided a very positive supervision for those who attended. The feedback we received each time was that it provided an opportunity for debriefing and extra input which was highly valued, particularly by those who were at remote sites and who expressed frustration about the paucity of supervision.

Recent developments and emphasis on continuing professional development (CPD) in the profession were perceived as being very positive and graduates reported the benefit derived from attending courses and meetings which provided access not only to new materials and information, but also to a network of supportive colleagues.

\section{Interpersonal issues}

\section{Interface with other professionals and with other SLTA/s}

All graduates have commented on the value of working in a team and of gaining further insight into the roles of the different team members in relation to the contexts and the disorders they worked with. Several commented also on the importance of transdisciplinary work.

"While the physiotherapist says $p$ - $p$ - $p$ I measure for a wheelchair."

A common theme with only one exception was on difficulties of interface with ENTs. There was a long waiting list for ENT services, poor follow up, lack of thorough examinations, poor referral patterns and very frustrating delays. Graduates at the few sites which employed Speech therapy assistants (STAs) commented on difficulties with working with this category and they indicated that they found working with Physiotherapy (PTAs) and Occupational therapy assistants (OTAs) easier. They did not see the need for STAs and their experience was mostly negative. They also commented that STAs had expressed dissatisfaction with their role, as well as working their conditions and salaries. Some graduates reported an interesting interface with community speech and hearing therapists, although they reported that the scope of practice of the latter was not always clear and in one instance the community speech and hearing therapist was in a supervisory 
role. They also found that working with SLP/A graduates from other universities enlightening and commented on the mutual benefit of this.

Some "turf battles" were reported with other professionals, for example on making diagnoses with, for example, psychologists, and some clashes with Occupational therapists who were working on early intervention and who were fitting hearing aids. They reported good relations with doctors but reported that at some sites there was an initial lack of respect. Some commented on the negative effect of doctor rotations as relationships were established and then the doctors moved on. In one hospital medical students observe speech therapy practice.

At one site, dysphagia patients were referred to dieticians and not to speech therapy and a partnership had to be developed. Generally there were no positive experiences reported with social workers and many expressed great difficulty and frustration with the process of acquiring disability grants on behalf of patients.

\section{Language and cultural issues}

Huge difficulties were initially reported in handling the linguistic diversity of caseloads and especially in dealing with foreign doctors and foreign patients. No formal interpreting services were reported but the use of ad hoc interpreters was widely reported and included the following: OTAs and Community-based Rehabilitation workers (CBRs), cleaners, nurses, other patients, volunteers, STAs, family members, PTAs, secretaries, community speech and hearing workers and SLT/As.

Those who had studied an African language as part of their course commented that it had not been particularly useful in practice and felt that the syllabus of that course needed revision. Further there was no guarantee that their working context would be one in which that language would be used. All graduates felt that some training in African languages should continue in a modified format but reported that on-site language learning had been effective and quick, especially where there was a predominant language spoken (as in KwaZulu-Natal) or when they had attended extra language classes. In 2008 there were fewer graduates highlighting such language issues as a major barrier. Hopefully this is a reflection of greater emphasis in the curriculum on addressing language diversity and working with interpreters (Penn, 2000). The changing profile of our student body may be another explanation. Another possibility exists: that some developed community placements now have more consistent and effective language strategies and services in place.

\section{Personal attributes}

Substantial discussion at each of the feedback meetings centred on the personal impact of CS and the individual influences on their development. Many reported an initial sense of isolation and the feeling of being overwhelmed and unable to handle the politics of the work environment in addition to the administrative demands:

"The politics were terrible; I don't think that new graduates should be exposed to the sort of things that we were exposed to."

Several were very concerned about safety and security issues (particularly given the transport inadequacies described above) and started using their own, more reliable cars. Some described their work as "heartbreaking" and expressed feelings of burnout and the need for debriefing and support. Most of the graduates reported developing strong informal networks of support CS professionals of other disciplines at their own sites, and through emails and telephonic contact and weekend visits with their fellow classmates and with other CS workers. Very few however indicated that this was formalized or regular. Many indicated that they had learned to take initiative and understood the notion of multitasking.

“My clinical skills haven't grown as much as I have as a person."

Several expressed frustration, but in their report back showed qualities of energy, humour and resilience.

"It's frustrating but challenging."

There was a growing awareness of their professional and personal value as well as of the value of CS:

"In KZN they want us, they love us, they welcome us!"

"I got a job straight after graduating."

A sense of purpose was also articulated:

"It seemed like a place I would make a difference."

Ellis (2004): "Once you just go there and be confident and learn from your mistakes."

"Trust your knowledge; you are well prepared and it's OK to say you don't know because when you do know your opinion will be trusted and appreciated".

\section{Ethical issues}

Contextual issues including the overriding influence of poverty, vulnerability and the burden of disease particularly for patients with HIV/AIDS, were frequently raised as a backdrop to some of the ethical problems identified by graduates.

"It was more kind of dealing with people who didn't have any money."

Particularly prior to the antiretroviral (ARV) rollout at government sites, graduates expressed considerable distress about the issues they were encountering and a sense of helplessness. Though there has been some alleviation in this regard, the harsh reality of daily exposure to death and the ravages of this disease have had a huge impact.

An analysis of the range of ethical issues described in the workshops revealed problems ranging on a continuum from what Purtilo (2006) describes as frank "moral distress" to issues which 
From pillars to posts: Some reflections on Community Service six years on

offered the opportunity for some active intervention and resolution. These findings correlated with some recent work with new graduates in Australia (Kenny, Lincoln, Blyth and Balandin, 2009). It became clear that in some cases graduates could identify the required course of action but were hampered from doing so and perceived that something harmful was ensuing. Examples of major challenges linked to being required to operate beyond recommended scope of competence. They also expressed concern about what they perceived as ethical violations on the part of other professionals, at managerial level and with nursing staff, and they were unsure as to how and to whom to "blow the whistle". They felt vulnerable when raising such issues and wondered about the impact on working relationships All graduates commented on the unique ethical demands of their placements and spoke about problem-solving strategies which had been developed. These problems further resulted in reported high levels of stress and burnout, confirming a study by Swidler and Ross (1993) and one by Dhaniram (2002) with CS doctors.

\section{Perceptions of Training}

All graduates were asked to comment on the training they had received and on their sense of preparedness for CS. The majority of graduates felt that their training had prepared them for most aspects of their jobs.

\section{"We know what we are doing."}

"You are more qualified than you think."

. "Wits trains you well to think on your feet and make decisions."

"Trust the knowledge you have acquired at Wits, but do continue reading."

They commented on the usefulness of lectures on counselling and community work, on the value of their hospital practical experiences and the value of their training and exposure to culturally diverse caseloads. Those who had had rural clinical practice in their undergraduate training commented specifically on its value in preparing them for CS. They found handouts provided during their training very useful and many commented on how helpful their training in sign language had been. The 2007 cohort made specific comments about the value of the resource portfolios which they had prepared over their studies (introduced after previous feedback from graduates).

Graduates also appeared to benefit from the service learning opportunity in their third year of study which involved the development of a workshop within a community of their choice (see Mophosho and Stein, 2009, for details of this component).

Some highlighted perceived gaps in their training: they felt the need for more input on budget writing, meeting protocol, developing home programmes, ENT procedures including cerumen removal and syringing, assertiveness skills, disability grants, how to write a motivational letter and a better understanding of legal issues around abuse, and of disability grants management. Some reported difficulties in doing home visits especially for very severely disabled patients. Suggestions about additions to the curriculum included a need for further input on AAC and early intervention, more practical opportunities in dysphagia, additional information about the management of motor neuron disease, specific information about ARVs and more first aid experience.

\section{Discussion}

For many of our graduates the CS became a life changing experience: "My outlook on life has changed."

In relation to community service for doctors, Couper (2002) has described the stages in the process as one of "culture shock": Fascination, Irritation, Depression, Adjustment. The feedback we have had from our own graduates suggests the validity of those phases, but it also suggests an even earlier "Overwhelmed" stage which seemed to be a common feeling of our graduates. This is reflected in Figure 1.

Interestingly in the one year (2006) when we had feedback at a slightly later stage of the year (August), we noticed a growth pattern in the stages our graduates had reached and we were surprised at the difference that even two months had made. These graduates seemed less overwhelmed, and there was pleasing evidence of adjustment, confidence and more proactive problem solving.

Most of our graduates themselves were able to describe these changes and growth across the year and were open about their early difficulties and their resolution towards the end of the year. They seemed aware of their limitations and described strategies to address them.

"For the first half of the year, I tried to avoid dysphagia as much as I could."

Several of our graduates applied for permanent posts in the same setting where they had worked but were often disappointed by the lack of availability of permanent posts.

In relation to the development of a process across the 6 years we have also seen positive changes. There appears to have been an improvement in equipment, referral systems and in recognition of the roles and function of the SLT/A in the team. Access to ARVs has made an important difference to caseloads.

Feedback on the adequacy of our program and the CS graduates' level of preparedness is increasingly improving. Our own curriculum has been modified substantially over the years to address the perceived gaps in the training - including larger modules on cerebral palsy, special input on working with interpreters (Penn, 2000), specialized and case-based input on ethical problem-solving, to mention but a few. We have reinstituted a rural practical, though this is expensive.

As a result of our graduates' feedback, we have also strengthened our commitment to produce graduates who can register 
Claire Penn, Anniah Mupawose and Jennifer Stein

both as speech language therapists and audiologists. According to the feedback we have had at this stage, there remain limited opportunities (and equipment) to employ singly qualified audiologists in the public sector and by far the majority of our graduates not only indicated a preference for a dual qualification, but also a level of preparedness for the type of problems they encountered, which they attributed to their training in both professions. This, however, should not detract from the urgent need to create an infrastructure supporting specialist qualifications in the future.

The feedback sessions have been immensely useful - serving as cathartic and informative opportunities and have helped us as educators to fine-tune our curriculum and methods. As a CPD service provider, our department has also implemented a series of workshops run in different provinces for multidisciplinary groups to address established needs: e.g. Dysphagia, Ethical problem solving for professionals, Working with Interpreters, HIV/ AIDS and Communication disorders, and Cerumen management.

In relation to CS for doctors, Reid (2001) suggested that the strategy of CS should be reviewed after five years to examine whether it is achieving the goal for which it was instituted. Six years on, our own profession also needs to take stock. For our recent graduates, how have the pillars of $\mathrm{PHC}$ and the new posts created, met the goals of CS? What indices can be used to measure the success of this initiative?

This is obviously a difficult challenge. One objective measure of success is to evaluate the proportion of recent graduates who stay in the country or people who are leaving because of community service (Reid, 2002). Another index might be to estimate the proportion of those who stay active in the profession (as there is a large drop-out rate) and of those, who choose to remain in public service. As Price and Weiner (2005) have pointed out in relation to the medical profession, the situation is complex. Reporting on a survey conducted with Wits medical graduates, they found that more graduates from the 1990 s are working in the public sector than before (over $60 \%$ ) and that more recent graduates had spent more time in the public sector especially in their early years. They highlight the methodological problems of such surveys, but assert the importance of considering the longitudinal career path of graduates and influences such as gender on the process - an important consideration in the case of our own professions. In Ellis' (2004) cohort, $61 \%$ of the CS SLT/As indicated that they would not choose to remain in their work setting if offered a permanent job, for personal and professional reasons.

We urge our own professional body to undertake a similar analysis of graduates by institution, province and decade, and to examine the number of individuals in this decade compared to the previous one, who have chosen not only to stay in the country but also to work in the public sector. Such an analysis might be very illuminating and will require a correlation with available posts for both speech-language therapists and audiologists.

A further index of success and one which we consider critical, is research. Pleasingly the benefit of $\mathrm{CS}$ has been an increase in the number of research projects at an undergraduate and postgraduate level which have been motivated by CS placements and experiences. This aspect is seen as a particularly important value of future enterprise, one apparently initially overlooked by the proponents of CS, but of vital importance to future status and survival of the profession (see Penn, 2007). Only through continued scientific research can our discipline hope to achieve due recognition and significantly influence policy. Most of the above indices of success can (and should) be analyzed by reference to data bases and by relevant quantitative methods. Much harder, of course, is the measurement of the impact of CS on aspects such as development of confidence and competence, person skills, management skills, negotiation skills, team skills - and ongoing evaluation of these aspects using suitable methods is important. We feel that the feedback process has provided significant insights and provided some opportunity to examine such factors. Surveys have some limitations, as Price and Weiner (2005) point out, but the focus group methods are useful in highlighting such aspects as Paterson et al. (2007) have found in relation to dieticians.

One criticism that could be levelled at the present study is that it incorporated Wits graduates only. However the presence of multiple auditors and independent observers at each meeting addresses issues regarding reliability to some extent. It is noteworthy that the graduates were widely dispersed and represented approximately $22 \%$ of all those working in CS each year throughout the country. At the time of the study, the Wits programme was one of the three programmes in the country graduating students with the option of dual registration (in both disciplines). Now there are only two such programmes. Clearly, equivalent studies on the graduates of other institutions would be useful and will add significantly to this body of preliminary evidence. Further longitudinal follow-up of graduates will provide additional perspectives, as Wheeler, Cross and Anthony (2000) have done in relation to nursing graduates.

\section{Conclusions and recommendations}

We conclude with some suggestions for research and some challenges for our professions. Community service has undoubtedly been one of the most important developments in the long history of the professions of Speech Language Therapy and Audiology in South Africa. The advent of CS has brought with it posts, novel employment opportunities and, as this paper suggests, a wealth of experience for new graduates. It has met the need of many hundreds of individuals for whom no previous services existed and for our own graduates it seems to have served as a refining and consolidating year for knowledge, skills and atti- 
tudes. Happily, in many cases, it has reinforced career choice, country of residence and site of future practice.

From our university's perspective, these feedback sessions have been profoundly valuable and have created a regular opportunity for self reflection which is a critical element of effective and dynamic educational practice (McAllister \& Lincoln, 2004). More than any other influence, these feedback sessions have helped to highlight gaps, strengths and provided in some cases a shift of focus in the curriculum. The settings have provided a range of opportunities for research and have provided innovation to our professions in terms of methods and problem solving skills. However, not all the implications lie at the University level. Much needs to happen at the DoH level (see Bateman, 2004). Some of the experiences of graduates in remote rural areas need to be heeded. For some, the experience has been profoundly negative:

"I think anybody who speaks to me will find that my CS experience was rather a lot like hell."

The DoH has a responsibility to take heed of such accounts and explore the reasons for these perceptions, and consider carefully the suitability of certain sites for the new graduate. Without the necessary level of support, the intention of CS in developing and retaining staff will be fruitless. Our results suggest that, especially for Audiology services, there has to be more emphasis placed on ENT services, better equipping of hospitals and other sites.

The creation of permanent and senior posts at each site is imperative to provide continuity and supervisory opportunities which will sustain the initial impetus and the goals of CS. In addition, better and consistent language services should be a feature of all sites and provision should be made for on-site training. The $\mathrm{DoH}$ should also encourage research as a relevant outcome of CS and support those wishing to do such research. The subsidisation of a rural practical for students in training would provide a helpful aid to preparedness.

For our professions, the feedback from recent graduates serves to provide evidence and impetus for a re-examination of scope and competency profiles for issues such as cerumen management and the profession should pursue its commitment to recognizing the need for specialist registers. The professional body should also continue to press for appropriate equipment, supervision, transport and support structures for members of its profession and explore interface with other professional bodies to ensure relevant referral opportunities. Some attention should be paid to the issues surrounding the training and scope of STAs. The profession has an ongoing ethical obligation to seek feedback from all graduates on the process and to undertake the relevant statistical analysis to understand better indices of success, or lack thereof, in CS. Such evidence is critical in formulating policy and changes of direction. Above all, the research aspect of our disciplines should not be neglected.
One of our graduates recently made the important observation that "Community service is what you make of it", but we believe that we can make it better and we remain committed to identifying and facilitating mechanisms at university, professional and national levels which will enable the achievement of this goal.

\section{Acknowledgements}

Thanks are due to all those Wits graduates who participated in our feedback sessions and whose ideas and voices form the basis of this article. We are deeply indebted to the Simmonds Hampton trust fund which has made this research possible. Thanks are also due to Heila Jordaan, Tanya Klugman, Dilys Jones, Nadine Ellis and Jennifer Watermeyer for their input on this project.

\section{References}

Aronson, J. (1994). A pragmatic view of thematic analysis. The Qualitative Report, 2, 1-4.

Bateman, C. (2004). Community service six years on... South African Medical Journal, 94, 408-409.

Benatar, S. (2004). Health care reform and the crisis of HIV and AIDS in South Africa. New England Journal of Medicine, 351 , 81-92.

Bortz, M., Schoub, B. \& McKenzie, J. (1992). Community work project in Gazankulu: a community-based training experience. South African Journal of Communication Disorders, 39, 62-68.

Couper, I. (2002). Culture Shock among New Doctors. South African Family Practice, 25(1), 17-18.

Dhaniram, N. (2002). Stress, burnout and salutogenic functioning amongst community service doctors in KwaZulu-Natal Hospitals. Unpublished Masters thesis, University of South Africa.

Department of Health. (1997). White Paper for the Transformation of the Health System in South Africa. Pretoria: Government Press.

Ellis, N. (2004). Preliminary study on Community Service Experience of Speech Therapy and Audiology graduates. Unpublished undergraduate research report, Department of Speech Pathology and Audiology, University of the Witwatersrand.

Kenny, B.J., Lincoln, M., Blyth, K., \& Balandin, S. (2009). Ethical perspective on quality of care; the nature of ethical dilemmas identified by new graduate and experienced speech pathologists. International Journal of Language and Communication Disorders, 44, 421-439.

Khan, N. (2002). My field experience as a CSP in the year 2002. Health KwaZulu-Natal: Community Service for Pharmacists. Retrieved November 10, 2008 from http:// www.kznhealth.gov.za/Pharmacists.htm

Koorts, A. (2004). The management of dysphagia by community service speech language therapists. Unpublished undergraduate research report, Department of Speech Pathology and Audiology, University of the Witwatersrand.

McAllister, L., \& Lincoln, M. (2004), Clinical education in Speech Language Pathology. Michigan: Whurr Publishers.

Mophosho, M., \& Stein, J. (2009). Learning about life: Academic service learning in the Department of Speech Pathology and Audiology, University of the Witwatersrand, South Africa. In M. Moore and P. Lan Lin (Eds.), Service-Learning in Higher Education: Paradigms and Challenges. Indianapolis: University of Indianapolis Press. 
Naidoo, S. \& Chitke, U. (2002). Community Dental Service - the first year. South African Dental Journal, 57(50), 193-196.

Naidoo, T. (2006). Audiological Practice and Service Delivery in South Africa. Unpublished Masters thesis, University of the Witwatersrand, Johannesburg, South Africa.

Nemutandani, M., Maluleke, F. \& Rudolph, M. (2006). Community service doctors in Limpopo Province. South Africa Medical Journal, 96(3), 180-182.

Paterson, M., Green, M. \& Maunder, E. (2007). Running before we walk: How can we maximise the benefits from community service dieticians in KwaZulu-Natal, South Africa? Health Policy, 82, 288-301.

Patton, M. (1990). Qualitative Evaluation and Research Methods ( $2^{\text {nd }}$ ed.). London: Sage Publications.

Penn, C. (2000). Cultural narratives: bridging the gap. South African Journal of Communication Disorders: Special edition on Communication Disorders in Multilingual Populations, 47, 71 78.

Penn, C. (2007). "Don't give me the theory, just tell me what to do in therapy": the slippery slope challenge for the South African professions of Speech Pathology and Audiology. South African Journal of Communication Disorders, 54, 13-17.

Price, M. \& Weiner, R. (2005). Where have all the doctors gone? Career choices of Wits medical graduates. South African Medical Journal, 95, 414-419.

Purtilo, R. (2006). Moral distress-the role of ethics consultation in the NICU. Journal of Clinical Ethics, 17, 358-363.

Reid, S. (2000). An overview of the first two years of community service. Health Systems Trust Update, Issue no. 57. Retrieved March 13, 2007 from htto://www.hst.org.za/uploads/files/ upd57.odf

Reid, S. (2001). Compulsory community service for doctors in South Africa-an evaluation of the first year. South African Medical Journal, 91, 329-336.

Reid, S. (2002). Community service for health professionals. South African Health Review. Retrieved March 13, 2007 from htto://www.hst.org.za/uploads/files/chapter8.odf

Roberts, C. (no date). Community service at Hlabisa and Madadeni. Retrieved October 6, 2008 from htto:// www.saslha.co.za/C-working-comserv.asp

Rule, S., Lorenzo, T. \& Wolmarans, M. (2006). Community-based rehabilitation: new challenges. In B. Watermeyer, L. Swartz, T. Lorenzo, M. Schneider, \& M. Priestley (Eds.), Disability and Social Change: A South African Agenda (pp. 273-290). Cape Town: HSRC Press.

Schneider, M. (1992). The care and management of communication disorders in a rural area: the role of the community speech and hearing therapy worker. South African Journal of Communication Disorders, 39, 55-61.

Swidler, M. \& Ross, E. (1993). Burnout: A smouldering problem -amongst South African speech-language pathologists and audiologists? South African Journal of Communication Disorders, 40, 71-84.

Wheeler, H., Cross, V. \& Anthony, D. (2000). Limitations, frustrations and opportunities: a follow-up study of nursing graduates from the University of Birmingham, England. Journal of Advanced Nursing, 32(4), 842-856. 